\begin{abstract}
The paper investigates the impact of financial integration on asset return, risk diversification and breadth of financial markets. We analyse a three-country macroeconomic model in which (i) the number of financial assets is endogenous; (ii) assets are imperfect substitutes; (iii) crossborder asset trade entails some transaction costs; (iv) the investment technology is indivisible. In such an environment, lower transaction costs between two financial markets translate to higher demand for assets issued on those markets, higher asset price and greater diversification. For the country left outside the integrated area, the welfare impact is ambiguous: it enjoys better risk diversification but faces an adverse movement in its financial terms of trade. When we endogenise financial market location, we find that financial integration benefits the largest economy of the integrated area. Only when transaction costs become very small does financial integration lead to relocation of markets in the smallest economy.
\end{abstract}

This paper was produced as part of the Centre's Globalisation Programme

\title{
Financial Integration and Asset Returns
}




\section{Philippe Martin and HJ IRe Rey}

March 2000 
Series Editor: Graham Ingham

Published by

Centre for Economic Performance

London School of Economics and Political Science

Houghton Street

London WC2A 2AE

(C) Philippe Martin and HJ IPne Rey, submitted September 1999

ISBN 0753013665

Individual copy price: , 5 


\section{Financial Integration and Asset Returns}

\section{Philippe Martin and HJ IPhe Rey}

1. Introduction 1

2. Model 3

3. Equilibrium Demand and Supply on Asset Markets 6

4. Welfare Implications of Financial Integration 9

$\begin{array}{ll}\text { 5. Endogenous Financial Market Location } & 10\end{array}$

$\begin{array}{ll}\text { 6. Conclusion } & 17\end{array}$

$\begin{array}{ll}\text { References } & 19\end{array}$

The Centre for Economic Performance is financed by the Economic and Social Research Council 


\section{Acknowledgements}

We thank Richard Baldwin, Pierre-Philippe Combes, Zvi Eckstein, Olivier Jeanne, Nobuhiro Kiyotaki, Peter Neary, Torsten Persson, Diego Puga, Lars Svensson, Fabrizio Zilibotti as well as seminar participants at the Institute for International Economic Studies and at ISOM for very helpful comments. We are especially grateful to Marco Pagano, Ken Rogoff, two referees and an editor for many excellent comments and suggestions. We also thank the Fondation Banque de France for financial assistance. 


\title{
Financial Integration and Asset Returns
}

\author{
Philippe Martin and HJ IRe Rey
}

\section{Introduction}

Trade in goods and goods market integration have been extensively studied. Asset flows and the impact of financial integration on the cost of capital and the breadth of financial markets have been comparatively far less researched ${ }^{1}$. What are the implications of being part of a large and financially integrated area for risk sharing and asset returns? In this paper, we show that when (i) the number of financial assets is endogenous, (ii) assets are imperfect substitutes, (iii) cross-border asset trade entails some transaction costs, and (iv) the investment technology is indivisible; then size and integration of financial markets are powerful determinants of the cost of capital. In particular, a decrease in transaction costs between two financial markets (the way we model financial integration) increases asset prices in the area, induces agents to develop more risky projects, increases the number of assets and pushes owners of projects to sell more of their project on the stock markets so that diversification increases ${ }^{2}$. This happens because a decline in transaction costs increases demand for assets in the area and so the effective size of the market is enlarged ${ }^{3}$. The presence of transaction costs and of imperfect substitutability translates this size effect into a price effect ${ }^{4}$. Because the number of assets is endogenous in our model, changes in the structure of financial markets also have an impact on the degree of incompleteness of financial markets and on aggregate risk.

What is the impact of regional financial integration on the rest of the world? We show that when two countries form a financial bloc, the welfare impact for the rest of the world is ambiguous. On the one hand there is a positive impact because the increase in the total number of assets enables agents to better diversify risk as markets become less incomplete. On the other hand, the financial terms of trade of the country left outside the financial bloc deteriorate because the price of assets in the integrated area increases.

These results are corroborated by recent empirical studies on the cost of capital. Evidence surveyed in Stulz (1999a) shows that financial integration decreases the cost of capital. Among others, Henry (1998) provides an event study of 12 liberalisations and finds stock abnormal returns of $4.6 \%$ per month on average in the 4 months before and the 3 months after the liberalisation date (with a total cumulative average return of $36.8 \%$ ). Bekaert and Harvey (1998) estimate that liberalisation decreases the dividend yield by 5 to 90 basis points. Hardouvelis et al. (1999) find that the average saving in the cost of capital from

\footnotetext{
$1 \quad$ For a discussion on the importance of these issues in the context of EMU, see Portes-Rey (1998).

$2 \quad$ Pagano (1993) also relates market size and breadth. For models where asset prices and liquidity (depth of a market, as opposed to breadth) are endogenised, see Pagano (1988), (1989).

3 These demand effects have been documented in the literature. Shleifer (1986) and Harris and Gurel (1986) showed that when a stock joins the S\&P500 index, there is an immediate additional demand which raises the price of the stock by 3 to $4 \%$.

$4 \quad$ In Martin-Rey (2000), we analyse in detail the size effect on asset prices as well as welfare and optimal policy. We also introduce a richer structure of transaction costs.
} 
integration in Europe over the period 1992-98 is around $2 \% 5$.

What happens to the geography and the relative importance of financial centres when we allow for international cross-listing of companies? We show that an entrepreneurs decision to list on one or several markets depends on the relative sizes of the various economies, as well as the relative magnitudes of the fixed and variable transaction costs that he faces. Fixed costs can be interpreted as differences in accounting procedures, legislation and information asymmetries across countries. Variable costs can be linked to proportional commissions and fees charged by various financial intermediaries, including foreign exchange transaction costs, as well as other types of informational asymmetries. The model delivers implications for the price of capital under dual listing, which depends on the relative size of economies.

These results are in line with empirical evidence on cross-listing, as surveyed in, for example, Karolyi (1998). Cross-listing is found to be associated with a small but significant decrease in the cost of capital. Our model predicts a positive effect on asset price in the case of double (or triple) listing due to a demand effect. The positive price effect is stronger: the larger the new financial area in which equities are issued; and the higher the transaction costs between the financial area where the stock was previously issued and the new financial area. Alexander, Cheol and Janakiraman (1988) study the effect of international listing on stock prices. They look at non-US firms, which get listed on the NYSE, and find a significant increase in their price. When they split their sample into Canadian and non-Canadian firms, they find that these effects are much weaker for the Canadian firms than for the others. This is what our model would predict if one believes that Canada's financial markets are relatively well-integrated (low transaction costs) with the US financial centres compared to the other countries. Miller (1999) looks at Depositary Receipts (DRs) ${ }^{6}$ to estimate the impact of international cross-listing. Based on a sample of 181 firms from 35 countries, he finds strong positive price effect of cross-listing. He also finds that the effect is larger in magnitude when the dual cross-listing takes place with a large stock exchange (NYSE or NASDAQ as compared to PORTAL).

Finally, our model predicts that the main determinants of gross equity flows are the size of economies and the trading and issuing costs. This is also consistent with the empirical evidence provided in Portes-Rey (2000) about bilateral gross equity flows.

As far as theory is concerned, the existing literature on trade under uncertainty pioneered by Helpman and Razin (1978) and Svensson (1988) has placed emphasis on comparative advantage $^{7}$. Size and demand effects play no role in the analysis and the set of assets traded is exogenously given. Gehrig (1998) discusses the delocalisation of financial centres as cost of market access and transaction cost decline. He argues that the fragmentation of information is the key element playing against the concentration of financial activity. Therefore, small stock exchanges will survive only if they are good providers of specialised local information. Pagano (1993) is the only theoretical paper we know of which endogenises the breadth of financial markets. He models very elegantly the flotation decisions of companies on the stock market. His analysis, which relies on a trading externality, differs from ours on several dimensions: in his model, the amount of shares traded is endogenous, but not the risky

\footnotetext{
$5 \quad$ From the theoretical side, Vayanos (1998) studies the impact of a decrease in transaction costs in an OLG, infinite horizon model. He shows the existence of two off-setting effects: on the one hand,

since the present discounted value of future transaction costs declines, asset price rises. On the other hand, stocks are held for a shorter time, so in equilibrium the marginal investor holds more of them and requires a higher risk premium, i.e. a lower price.

6 A DR is a certificate issued by a depositary bank for non-US securities that are held by a custodian in the home market of the non-US. DRs trade like any other US security.

$7 \quad$ Persson and Svensson (1989) and Svensson (1989) introduce money and discuss the impact of monetary

policy on nominal asset trade.
} 
investments themselves; he looks exclusively at a closed economy environment; moreover the pay-off structure of the assets, as well as the transaction costs structure are different from ours ${ }^{8}$.

More closely related to our modelling approach is the work of Acemoglu and Zilibotti (1997), which builds on a market structure (endogenous number of Arrow-Debreu projects) similar to ours, except that it is embedded in a competitive environment while we have elements of monopolistic competition. They focus exclusively on capital accumulation and growth, and the issue of financial market integration is left aside. Unlike them, we emphasise the interaction between the incompleteness of markets, the size of markets and the price of financial assets in an international environment.

We present the model in Section 2 Section 3 derives the equilibrium demands and supplies on asset markets. Section 4 analyses welfare implications of financial integration in a three-country world. Endogenous location decisions (cross-listing) are studied in Section 5, as well as the impact on market capitalisation of a decrease in transaction costs and of institutional harmonisation within the integrated area. Section 6 concludes.

\section{Model}

The general framework is similar to Martin and Rey (2000) where we analyse a two-country version, albeit in a more general set-up. Here, we extend the model to a set of three countries, $\mathrm{A}, \mathrm{B}$ and $\mathrm{C}$, so as to study the impact of financial integration in a subset of two of these countries.

\section{Physical environment and timing}

Countries are populated with $\mathrm{n}_{\mathrm{j}}, \mathrm{j} \in\{\mathrm{A}, \mathrm{B}, \mathrm{C}\}$, risk averse immobile identical agents where the subscript identifies the country. The model has two periods. In the first period all agents in the world are endowed with y units of a freely traded good (the numéraire) which they can choose to consume or invest in fixed size risky projects. During the second period, Nature chooses between $\mathrm{N}$ equally likely states. $\mathrm{M}$ different projects are developed with the following second period pay-offs:

$$
\text { project i pays }=\left\{\begin{array}{l}
\mathrm{d} \text { if state } \mathrm{i} \in \mathrm{N} \text { occurs } \\
0 \text { otherwise }
\end{array}\right.
$$

Shares of these projects are traded on the stock markets of the three countries. This implies that investing in a specific project (either directly or through the stock market) is equivalent to buying an Arrow-Debreu asset that only pays in one state of nature. This formalisation is close to the one developed by Acemoglu and Zillibotti (1997). It captures an essential feature of the model: different projects and assets are imperfectly correlated so that assets are imperfect substitutes and variety improves safety ${ }^{9}$. The fixed size investment projects are equally costly to develop and give the same dividend $\mathrm{d}$. An agent $\mathrm{h}_{\mathrm{j}} \in\left\{1, \ldots \mathrm{n}_{\mathrm{j}}\right\}$ chooses to develop $\mathrm{z}_{\mathrm{hj}}$ different projects. The choice of the projects is public knowledge. This implies that $\mathrm{M}$, the

\footnotetext{
8 Lombardo and Pagano (1999) model the impact of differences in legal environments on the breadth of financial markets and on asset returns.

9 The correlation between our assets is -1 . We conjecture however that our qualitative results are valid 
total number of projects (and assets) in the world is: $\sum_{h=1}^{n_{A}} z_{h A}+\sum_{h=1}^{n_{B}} z_{h B}+\sum_{h=1}^{n_{C}} z_{h C}$ because, in equilibrium, agents will have no interest in duplicating a project that has already been developed and all agents of a same country will develop the same number of projects. Denote by $\mathrm{M}_{\mathrm{j}}$ the set of projects that have been developed in each country $\mathrm{j}$ so that the total number of assets in the world is $M=M_{A}+M_{B}+M_{C}$. We will restrict parameters so that $\mathrm{M}<\mathrm{N}$ markets will not be complete. It will not be possible to eliminate all risk by holding a portfolio of all traded assets because for some states of the world, a corresponding asset will not exist. Hence the matrix of the pay-offs will be the following:

$\left[\begin{array}{c|c}d \mathrm{I}_{M} & O_{M, N-M} \\ \hline O_{N-M, M} & O_{N-M, N-M}\end{array}\right]$ where $\mathrm{I}_{\mathrm{M}}$ is the identity matrix of rank $\mathrm{M}$ and $\mathrm{O}_{\mathrm{I}, \mathrm{J}}$ is the null matrix with

I rows and $\mathrm{J}$ columns.

The cost of each new project is increasing with the number of projects an agent is performing because we assume that the monitoring of each project becomes more complex and costly as the numbers of projects increase. Hence, the total cost in units of the numéraire of the investment in risky projects of an agent $h_{j}$ is $f\left(z_{h j}\right)$, where $f^{\prime}$ and $f^{\prime \prime}>00^{10}$. There is no restriction to develop new projects and this will determine the equilibrium number of projects and therefore the equilibrium number of assets. In addition, during the first period, agents sell shares of their projects and buy shares of other projects.

\section{Transaction costs}

The second essential feature of the model is the presence of international transaction costs on asset markets. When agents trade assets, they incur a transaction cost $\tau$, which is paid in units of the share itself when the share is traded. The same transaction cost also applies to the stochastic dividend and is paid in units of the dividend ${ }^{11}$. The transaction cost is modelled as an iceberg cost: part of the share and part of the dividend "melt" during the transit. The presence of international transaction costs on the trade in assets captures different types of costs: (1) banking commissions and variable fees; (2) exchange rate transaction costs; (3) exchange rate changes related risk that is costly to insure; (4) some information costs ${ }^{12}$.

In this first section, where the geography of financial markets is given in order that project developers sell their assets on their national stock markets only, we assume that agents who buy foreign assets have to bear the transaction cost. Hence, the cost of an asset of a project developed in country $\mathrm{j}$ and bought by an agent of country $\mathrm{k}$ is: $p_{j}\left(1+\tau_{k j}\right)$ where $\tau_{k j}$ is the transaction cost between markets of countries $\mathrm{k}$ and $\mathrm{j}$. We call $s_{h \mathrm{~A}}^{j}$ the demand by an agent in $\mathrm{A}$

\footnotetext{
10 Theoretically $\mathrm{f}$ is defined on ${ }^{`}$. However we will study the extension of $\mathrm{f}$ on ${ }^{\circ}$ to be able to use derivatives and simplify the exposition. We will then restrict the set of the solutions of the optimisation problem to belong to ${ }^{\circ}$.

11 We assume that these transaction costs cannot be evaded by going through the goods market on which, for convenience, we assume no transaction costs. The transaction cost could be eliminated either on

the purchase of assets or on the dividends without changing any of our qualitative results. 12 Later on, we consider also fixed costs, which could account for difference in regulations and accounting principles as well as for other types of information costs.
} 
of an asset of country $j$ In the rest of the paper, superscripts will identify the seller and subscripts the buyer. If this particular asset pays a dividend $\mathrm{d}$ in period 2, then a shareholder in the foreign country will receive only $(1-\tau) \mathrm{d}$ per share.

\section{Budget constraint}

The budget constraint for an agent $\mathrm{h}_{\mathrm{A}}$ in country $\mathrm{A}$ is:

$$
c_{1 h_{A}}+f\left(z_{h_{A}}\right)+\sum_{i \notin z h A}^{M_{A}} p_{i} s_{h_{A}}^{i}+\sum_{j}^{M_{B}}\left(1+\tau_{A B}\right) p_{j} s_{h A}^{j}+\sum_{j}^{M_{C}}\left(1+\tau_{A C}\right) p_{j} s_{h A}^{j}=y+\sum_{k}^{z_{h_{A}}} p_{h_{A}}^{k} \alpha_{h_{A}}^{k}
$$

where $c_{1 h A}$ is consumption of agent $h_{A}$ in period 1 . The second term on the left-hand side is the cost of investment in risky projects. The last terms on the left-hand side represent the demands for domestic and foreign assets. There are $\left(\mathrm{M}_{\mathrm{A}}-\mathrm{z}_{\mathrm{hA}}\right)$ different domestic assets that agent $\mathrm{h}_{\mathrm{A}}$ demands as he will only buy assets of projects he has not developed himself. There are (M$\mathrm{M}_{\mathrm{A}}$ ) different foreign assets on which he incurs the transaction cost $\tau_{\mathrm{AB}}$ and $\tau_{\mathrm{AC}}$. On the revenue side, in addition to endowment $\mathrm{y}$, agent $\mathrm{h}_{\mathrm{A}}$ sells a portion $\alpha_{h_{A}}^{k}$ of each project $\mathrm{k} \in \mathrm{z}_{\mathrm{hA}}$ that he has developed. The budget constraint of agents in countries B and $\mathrm{C}$ are symmetric.

\section{Preferences}

The utility of an agent $\mathrm{h}_{\mathrm{A}}$ in country A has the following form:

$$
U_{h_{A}}=c_{1 h_{A}}+\beta E\left(\frac{c_{2 h_{A}}^{1-1 / \sigma}}{1-1 / \sigma}\right)
$$

where $\beta$ is the rate of discount of the future and $s$ is bigger than one ${ }^{13}$. The utility of agents in countries B and $\mathrm{C}$ are similar. $\sigma$ is the inverse of the degree of risk aversion. It is also the elasticity of substitution between assets. The state of the world is revealed in the beginning of the second period.

Agents maximise expected utility under their budget constraint. Agent $\mathrm{z}_{\mathrm{hA}}$ in country A chooses consumption in period $1, \mathrm{c}_{1 \mathrm{hA}}$, the number of projects $\mathrm{Z}_{\mathrm{hA}}$ he will develop, the demands for the different assets (domestic and foreign) and the portion of each of his projects that he will retain in the second period: $1-\alpha_{h_{A}}^{k}$ for each project/asset $\mathrm{k} \in \mathrm{z}_{\mathrm{hA}}$. Agents are price takers when they buy shares on the stock market. Note also that agents do not internalise the impact they have on other agents' welfare when they optimise. In particular, they do not internalise the impact that the choice of the number of projects per agent has on the possibility for other agents to diversify risk ${ }^{14}$. The fixed cost that is required to develop a new project also insures that no agent will ever find optimal to replicate an already existing project. The reason is that if he were to do so, the supply of the corresponding asset would necessarily increase so that its equilibrium price would decrease. It will therefore be more profitable to develop a project that has not yet been opened.

\footnotetext{
13 In Martin and Rey (2000), we discuss more general utility functions. The linearity of the utility function

in the first period suppresses wealt
This is similar to Pagano (1993).
} 


\section{Market structure}

Note that each agent has a potential power of monopoly on the projects that he has developed and therefore on the sale of the assets that correspond to these projects. This is a departure from the Arrow-Debreu world where asset markets are assumed to be perfectly competitive. It is easy to check that the perceived elasticity of demand for any asset $\mathrm{k}$ with respect to its price is: $\left(\partial \alpha^{\mathrm{k}} / \partial \mathrm{p}^{\mathrm{k}}\right) /\left(\alpha^{\mathrm{k}} / \mathrm{p}^{\mathrm{k}}\right)=-\sigma, \mathrm{k} \in \mathrm{M}$. The owner of the asset will use this monopolistic structure and will sell only a portion of his project. This means that in equilibrium the developer of the project will remain the largest shareholder of the project.

Because all agents in a same country are identical and the projects are symmetric, the demand for assets of a given country by agents of the same nationality will be symmetric. Even though agents, in equilibrium, will not be identical because they will hold different amounts of the different assets, they will be symmetric in the sense that their diversification choice will be identical. Also, the price of all projects/assets developed by agents of a same country will be identical for the same reason. Hence, from now on we will generally omit notations that refer to the identity of the agents and of the assets. As for the demand for assets, the superscript denotes the origin of the asset and the subscript denotes the nationality of the buyer. For example, $s_{A}^{B}$ is the demand for an asset of country B by an agent of country A. Using the first order conditions for an agent in A the demand for different assets are given by:

$$
\begin{aligned}
& s_{A}^{A}=\left(1-\alpha_{A}\right)\left(\frac{\sigma-1}{\sigma}\right)^{\sigma}=p_{A}^{-\sigma}\left(\frac{\beta}{N} d^{1-1 / \sigma}\right)^{\sigma} ; \\
& s_{A}^{B}=p_{B}{ }^{-\sigma}\left(\frac{\beta}{N} d^{1-1 / \sigma}\right)^{\sigma} \frac{\left(1-\tau_{A B}\right)^{\sigma-1}}{\left(1+\tau_{A B}\right)^{\sigma}} ; s_{A}^{C}=p_{C}{ }^{-\sigma}\left(\frac{\beta}{N} d^{1-1 / \sigma}\right)^{\sigma} \frac{\left(1-\tau_{A C}\right)^{\sigma-1}}{\left(1+\tau_{A C}\right)^{\sigma}}
\end{aligned}
$$

The demand by agents in $\mathrm{B}$ and $\mathrm{C}$ are symmetric. Note that the first equation implies that there is not full diversification even of the domestic portfolio. Agents keep more of their own project than they buy of projects developed by other agents in the same country as: $s_{A}^{A}<1-\alpha_{A}$. This is due to imperfect competition on the asset market as project owners have an incentive to retain some portion of it to exploit their monopolistic power. This implies that in equilibrium projects have a nationality: one agent owns more of the project than any other agent in the world. The two last lines imply that the demand for assets decreases in price and the demand for foreign assets decreases in the transaction cost.

\section{Equilibrium Demand and Supply on Asset Markets}

Using first order conditions and the equilibrium condition on the market for each asset, we can derive the portion of shares of the projects that are sold on the different stock markets:

$$
\begin{aligned}
& \alpha_{A}= \frac{n_{A}-1+n_{B} \phi_{A B}+n_{C} \phi_{A C}}{n_{A}-1+n_{B} \phi_{A B}+n_{C} \phi_{A C}+\left(\frac{\sigma}{\sigma-1}\right)^{\sigma}} ; \alpha_{B}=\frac{n_{B}-1+n_{A} \phi_{A B}+n_{C} \phi_{B C}}{n_{B}-1+n_{A} \phi_{A B}+n_{C} \phi_{B C}+\left(\frac{\sigma}{\sigma-1}\right)^{\sigma}} \\
& \alpha_{C}=\frac{n_{C}-1+n_{A} \phi_{A C}+n_{B} \phi_{B C}}{n_{C}-1+n_{B} \phi_{B C}+n_{C} \phi_{B C}+\left(\frac{\sigma}{\sigma-1}\right)^{\sigma}}
\end{aligned}
$$


where $\phi_{i j}=\left(\frac{1-\tau_{i j}}{1+\tau_{i j}}\right)^{\sigma-1} ; i, j=A, B, C$ and is decreasing in transaction costs. The asset prices in the three countries are:

$$
\begin{aligned}
& p_{A}=\frac{\beta}{N} d^{1-1 / \sigma}\left[n_{A}-1+n_{B} \phi_{A B}+n_{C} \phi_{A C}+\left(\frac{\sigma}{\sigma-1}\right)^{\sigma}\right]^{1 / \sigma} \\
& p_{B}=\frac{\beta}{N} d^{1-1 / \sigma}\left[n_{B}-1+n_{A} \phi_{A B}+n_{C} \phi_{B C}+\left(\frac{\sigma}{\sigma-1}\right)^{\sigma}\right]^{1 / \sigma} \\
& p_{C}=\frac{\beta}{N} d^{1-1 / \sigma}\left[n_{C}-1+n_{A} \phi_{A C}+n_{B} \phi_{B C}+\left(\frac{\sigma}{\sigma-1}\right)^{\sigma}\right]^{1 / \sigma}
\end{aligned}
$$

Since there is free entry in the market of investment projects, each agent will develop projects up to the point where the marginal cost is equal to its price:

$$
f^{\prime}\left(z_{A}\right)=p_{A} ; f^{\prime}\left(z_{B}\right)=p_{B} ; f^{\prime}\left(z_{C}\right)=p_{C}
$$

Because of the convexity of the cost function, the number of projects developed by an agent increases with the price of assets ${ }^{15}$. Note that unlike Pagano (1993), we do not have multiple equilibria. This is because the marginal utility of being insured against one state of nature and therefore the price of an asset in our model is independent of the number of existing assets. Hence agents decide whether or not to develop a project independently of the decisions of other agents. Moreover, since there are no issuing costs, they can only be better off by selling their asset on the market. And since purchasers of assets, unlike in Pagano's model, do not face a fixed cost to gain access to the market, there are no strategic complementarities.

If we interpret financial integration as a decrease in transaction costs between two countries, we can analyse its impact by simple comparative statics. For example, the decrease in transaction costs between markets $\mathrm{B}$ and $\mathrm{C}$ have a positive impact on prices $\left(\frac{\partial p_{B}}{\partial \phi_{B C}}>0 ; \frac{\partial p_{C}}{\partial \phi_{B C}}>0\right)$ and financial diversification $\left(\frac{\partial \alpha_{B}}{\partial \phi_{B C}}>0 ; \frac{\partial \alpha_{C}}{\partial \phi_{B C}}>0\right)$ in those two countries. Both price and financial diversification in A are unaffected by financial integration between $B$ and $C$. It is also easy to check that the price elasticity with respect to a change in transaction costs is higher in the small country than in the large country.

The increase in the asset prices of the financially integrated area induces agents of the zone to develop more risky projects in order that the number of assets offered will also increase. For each project, the portion sold on the stock market will increase. Hence, turnover on financial markets in the bloc should increase not only because some new projects will be floated but also because owners of existing projects will choose to increase portfolio diversification and sell more of their own projects.

The intuition of these results is best understood by analysing the determinants of supply and demand of assets in our framework. The choice of the portion of each project which is sold on the market $(\alpha)$ is derived from first order conditions: agents set the marginal cost of doing 
this equal to the marginal gain (the Lagrangian is equal to 1 because of linearity of utility in first period) so that:

$$
\frac{\beta}{N} d^{1-1 / \sigma}\left(1-\alpha_{i}\right)^{-1 / \sigma}=p_{i}\left(\frac{\sigma-1}{\sigma}\right) \quad i=A, B, C
$$

The expected marginal cost of selling one more share of the project developed by the agent is the expected welfare loss due to consumption thus foregone (left hand side of the equation). Note that because of the concavity of expected utility in consumption ( $\sigma$ positive), this marginal cost is naturally rising with the portion of the project sold. The marginal gain is less than the price of the asset as an increase in the supply of the asset implies a decrease in its price. At the optimum, the price of a share is equal to its marginal cost multiplied by the mark up $\sigma /(\sigma-1)$. The aggregate demands for a typical asset of each country are the following:

$$
\begin{aligned}
\alpha_{A} & =\left(\frac{\beta d^{1-1 / \sigma}}{N}\right)^{\sigma} p_{A}^{-\sigma}\left(n_{A}-1+n_{B} \phi_{A B}+n_{C} \phi_{A C}\right) \\
\alpha_{B} & =\left(\frac{\beta d^{1-1 / \sigma}}{N}\right)^{\sigma} p_{B}^{-\sigma}\left(n_{B}-1+n_{A} \phi_{A B}+n_{C} \phi_{B C}\right) \\
\alpha_{C} & =\left(\frac{\beta d^{1-1 / \sigma}}{N}\right)^{\sigma} p_{C}^{-\sigma}\left(n_{C}-1+n_{A} \phi_{A C}+n_{B} \phi_{B C}\right)
\end{aligned}
$$

They are decreasing in price and also in transaction costs. Hence, financial integration between markets $\mathrm{B}$ and $\mathrm{C}$ (an increase in $\phi_{\mathrm{BC}}$ ) induces agents of $\mathrm{B}$ to demand more of assets of $\mathrm{C}$ and vice versa. We can analyse the effect of financial integration on a simple graph where the supply and demand of a typical asset are illustrated. In this example, we assume that the three countries are initially identical in size and degree of financial integration: 


\section{Graph 1: financial integration, asset price and diversification}

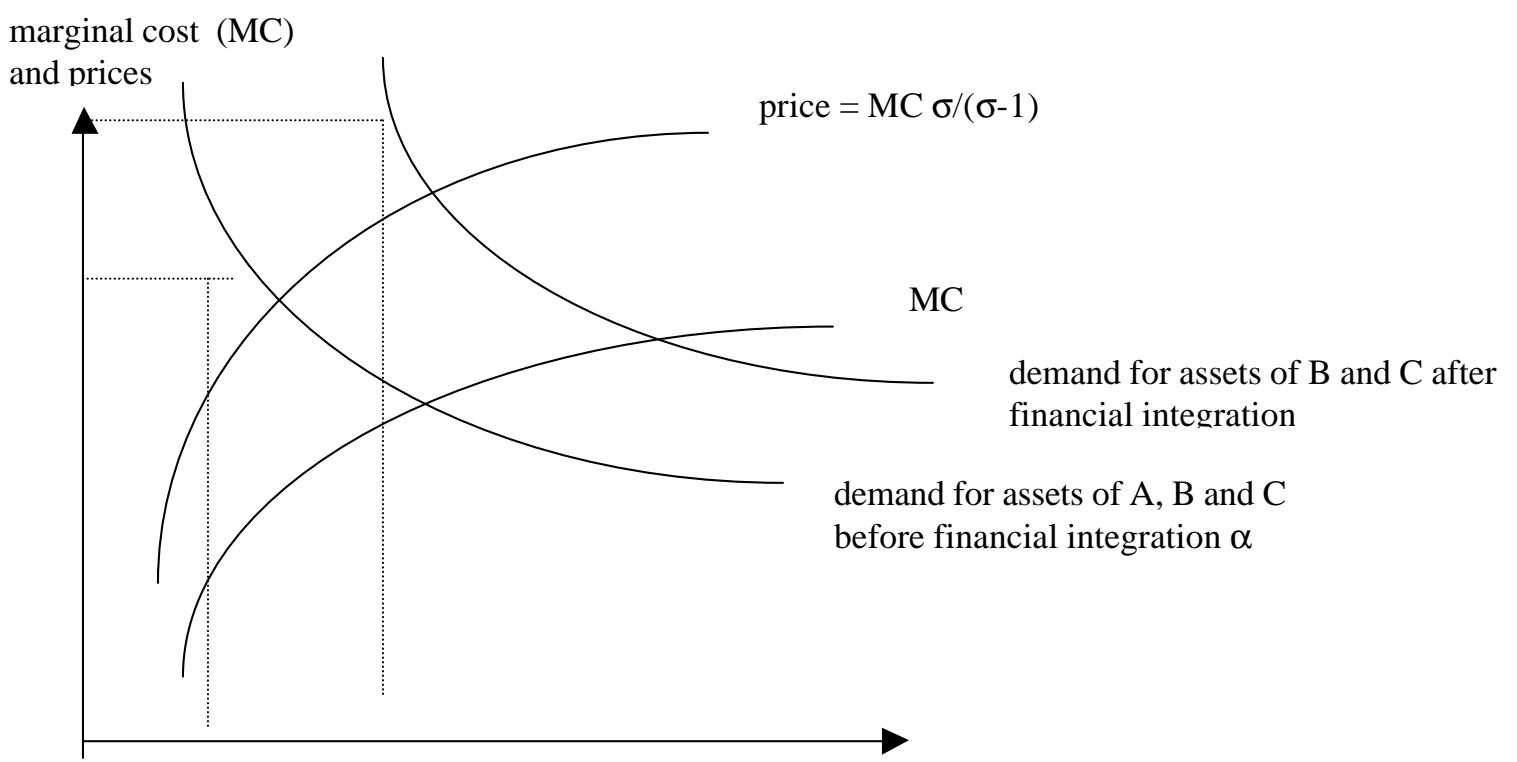

Financial integration implies a shift in the demand curve so that in equilibrium it leads to increased asset prices in $\mathrm{B}$ and $\mathrm{C}$ and to increased financial diversification (the portion of a typical investment sold on the market) in these two countries. The result comes from two essential features of our model. First, the existence of transaction costs between markets with a segmentation effect that gives a role to local demand in the determination of asset price. Second, the assumption that assets are imperfect substitutes or that agents are risk averse. In our model, this turns out to be the same because the elasticity of substitution between assets $\sigma$ is the inverse of the degree of risk aversion. Without risk aversion, there would be no portfolio diversification, no demand for foreign assets and financial integration would have no impact.

\section{Welfare Implications of Financial Integration}

We now want to analyse the impact of reducing transaction costs between markets $\mathrm{B}$ and $\mathrm{C}$ on the welfare of countries $\mathrm{A}, \mathrm{B}$ and $\mathrm{C}^{16}$.

Indirect expected utility for an agent in country B is given by:

$$
\begin{aligned}
& U_{B}=y+p_{B} z_{B} \alpha_{B}-f\left(z_{B}\right)-\left(n_{B}-1\right) z_{B} p_{B} s_{B}^{B}-\left(1+\tau_{A B}\right) n_{A} z_{A} p_{A} s_{B}^{A}-\left(1+\tau_{B C}\right) n_{C} z_{C} p_{C} s_{B}^{C}+ \\
& \frac{\beta}{N} \frac{d^{1-1 / \sigma}}{1-1 / \sigma}\left[\begin{array}{l}
\left(n_{B}-1\right) z_{B} s_{B}^{B^{1-1 / \sigma}}+n_{A} z_{A} s_{B}^{A^{1-1 / \sigma}}\left(1-\tau_{A B}\right)^{1-1 / \sigma} \\
+n_{C} z_{C} s_{B}^{C^{1-1 / \sigma}}\left(1-\tau_{B C}\right)^{1-1 / \sigma}+z_{B}\left(1-\alpha_{B}\right)^{1-1 / \sigma}
\end{array}\right]
\end{aligned}
$$

The indirect utilities of $\mathrm{A}$ and $\mathrm{C}$ are symmetric. Because the price of assets in $\mathrm{A}$ and the demand for assets in A are not affected by the change in the transaction costs between B and

\footnotetext{
16 In Martin and Rey (2000), we analyse the market failure that exists in this model due to imperfect competition on the asset market and also due to the externality in the choice of the number of projects per agent. We show that in the market equilibrium, the price of assets is too high, the diversification 
$\mathrm{C}$, it is easy to show that the welfare in B rises with a decrease in transaction costs between $\mathrm{B}$ and $\mathrm{C}$ if this is the case for the following expression:

$$
p_{B} z_{B}-f\left(z_{B}\right)+\frac{1}{\sigma-1}\left(\frac{\sigma-1}{\sigma}\right)^{\sigma} p_{B}\left(1-\alpha_{B}\right)\left[z_{B}\left(n_{B}-1\right)+\phi_{B C} z_{C} n_{C}\left(\frac{p_{B}}{p_{C}}\right)^{\sigma-1}\right]
$$

It can be shown that this expression is increasing in $\phi_{\mathrm{BC}}$, and therefore welfare in B increases with financial integration. There are three types of gain for the agents who are part of the financially integrated area. (1) The value of assets held by agents in B rises relative to the price of assets in A and so there is a positive financial terms of trade effect for agents in B. (2) Because the prices of assets in $\mathrm{B}$ and $\mathrm{C}$ rise, the total numbers of assets rise as agents in the financially integrated area are induced to invest in more risky projects. This reduces risk at the world level and is beneficial for all agents. (3) Finally, there is a direct effect due to the fact that the cost of diversifying risk and buying assets in $\mathrm{C}$ has decreased. This benefit is greater when the number of assets offered on the stock market of $\mathrm{C}$ is larger. It can be shown that the positive welfare effect of the decrease in transaction costs is larger for the smallest country.

The impact of financial integration between $\mathrm{B}$ and $\mathrm{C}$ on the welfare of agents in $\mathrm{A}$ is ambiguous. In the simple case where $\mathrm{B}$ and $\mathrm{C}$ are identical, it can be shown that welfare in $\mathrm{A}$ increases in $\phi_{\mathrm{BC}}$ if the following expression also increases in $\phi_{\mathrm{BC}}: p_{B}{ }^{1-\sigma} z_{B}$. The condition for this to be the case is: $f^{\prime}\left(z_{B}\right)-(\sigma-1) z_{B} f^{\prime \prime}\left(z_{B}\right)>0$ which implies:

$$
\frac{\partial z_{B}}{\partial p_{B}} \frac{p_{B}}{z_{B}}>\sigma-1
$$

This condition implies that the elasticity of the number of projects developed with respect to the price of shares must be large enough for agents in A to gain from financial integration between $\mathrm{B}$ and $\mathrm{C}$. There are two opposite effects of financial integration that explain this result for A. On the one hand, country A suffers from a negative financial terms of trade effect as agents in A must now pay a higher price to diversify risk when buying assets from B and C. On the other hand, the increase in asset prices in the financially integrated area induces agents of the area to develop new risky projects. This produces a positive externality for all agents as they can better diversify against risk. This positive effect is larger when the elasticity of $\mathrm{z}$ with respect to the asset price is higher. When $\sigma$ is high relative to this, the demand for assets responds a lot to changes in price so that the loss due to the terms of trade deterioration is important. It also implies that because agents are not very risk averse the gain due to the higher number of assets in the world is not very large.

\section{Endogenous Financial Market Location}

Our model can be used in particular to think about the impact of financial integration on financial markets location. The following questions have come up in Europe on this issue: will London or Frankfurt gain or lose financial activities because of financial integration and the creation of the euro ${ }^{17}$ ? Will the decrease in transaction costs imply that peripheral firms cease issuing their assets in "peripheral" financial centres and if so will this agglomeration

$17 \quad$ We interpret the creation of the euro as a phenomenon decreasing variable costs linked to foreign exchange transactions. The euro is also a catalyst for concentration and cost cutting in the financial industry. Although it could be argued that the birth of the euro also increases the substitutability of 
phenomenon benefit a large outside market such as London or an insider such as Frankfurt? If we think of country A as the UK, country B as Germany and country C as all other countries in the euro zone, we can use our model to analyse these questions.

Most of the results of this section will depend on the relative magnitudes of the fixed and variable costs that agents incur in the various countries to get listed on stock exchanges or to engage in equity trade. We will show in particular that if financial integration implies a decrease in variable transaction costs, then it should increase the incentive to issue shares on the largest market of the integrated area: Frankfurt would gain market share at the expense of other markets outside the euro zone and also at the expense of other markets in the euro zone. But if financial integration induces institutional harmonisation (a decrease in the fixed cost of issuing abroad within the integrated area), then the incentive to issue shares on both markets of the integrated area, including the smallest one, increases. In the extreme case where the fixed cost of issuing in a foreign market disappears entirely inside the integrated zone as well as transaction costs inside the zone, then location of the financial market inside the zone is indeterminate.

\section{Fixed costs, variable costs and endogenous listing decisions}

Up to now, we have assumed that agents issue assets in their own country only. A system where they can issue assets in the other country and pay the transaction costs themselves would be identical as the transaction cost would be fully passed to asset buyers. Hence, to make the question of endogenous market location interesting in this model we need to introduce some new elements. First, we assume that there exists a fixed cost of issuing an asset on a market, which is equal to $F$ on all three markets. It does not depend on the amount of shares sold, just on the number of assets issued. Second, there is an extra fixed cost $c$, that the issuer must pay if he issues the asset on a foreign market ${ }^{18}$ Therefore, the fixed cost if he issues only on his own market is $F$ per asset issued. The cost is $F+c$ per asset if he issues only in a foreign market, $2 F+c$ per asset if he issues on the domestic and one foreign market and $3 F+2 c$ if he issues on all three markets. In this latter case, buyers pay no international transaction cost. The fixed costs are paid in units of $y$.

In this section, we assume that country $\mathrm{A}$ is a large country, country B a medium sized country and country $\mathrm{C}$ a small country $\left(n_{A}>n_{B}>n_{c}\right)$. We look at the impact of decreasing transaction costs between $\mathrm{B}$ and $\mathrm{C}$ on the location(s) project owners choose to issue their assets. The decision on which market to issue assets will be based on the comparison of profits a project owner gets (the comparison in terms of indirect utility is identical).

\section{Project owner of country A}

We first look at the choice of a project owner in country A. It is easy to show that such an agent will never choose to issue his assets only in market $\mathrm{C}$ or in markets $\mathrm{A}$ and $\mathrm{C}$. In this context, a small country can never become a financial centre. The reason is that in addition to the extra cost of issuing in a foreign country, the small domestic demand in $\mathrm{C}$ is a disadvantage due to the presence of international transaction costs. For the small market to become a financial centre, such as an off-shore financial centre, it would need to attract issuers by offering a smaller fixed cost $F$ than the large markets. In this case, the lower the international transaction costs the

assets, this is not the line we take here

This cost reflects in particular the changes in accounting standards and procedures, which are required

list on other stock exchanges. The compliance to the GAAP for instance is a major fixed cost for non US companies wishing to be listed on the NYSE. 
greater the possibility that small countries with low fixed costs of issuing assets will become financial centres.

Hence, the relevant alternatives for $\mathrm{A}$ are to issue in all three markets (A, B and C), to issue in both $\mathrm{A}$ and $\mathrm{B}$ and to issue in $\mathrm{A}$ only. The profit of issuing in market $\mathrm{A}$ is:

$$
p_{A} z_{A}-f\left(z_{A}\right)-F z_{A}=z_{A} f^{\prime}\left(z_{A}\right)-f\left(z_{A}\right) ; p_{A}=f^{\prime}\left(z_{A}\right)+F
$$

where $p_{A}$ is given in equation (5). Because of the fixed cost, $z_{A}$ here is smaller than in the previous section. Note that the profit of issuing in A only does not depend on transaction costs between markets $\mathrm{B}$ and $\mathrm{C}$. If this agent was to issue on markets $\mathrm{A}$ and $\mathrm{B}$, the profit would be:

$$
p_{A B} z_{A B}-f\left(z_{A B}\right)-2 F z_{A B}-c=f^{\prime}\left(z_{A B}\right) z_{A B}-f\left(z_{A B}\right) ; p_{A B}=f^{\prime}\left(z_{A B}\right)+2 F+c
$$

where $p_{A B}$ is the price of an asset issued on markets $\mathrm{A}$ and $\mathrm{B}$ and is given by:

$$
p_{A B}=\frac{\beta}{N} d^{1-1 / \sigma}\left[n_{A}-1+n_{B}+n_{C} \phi_{B C}+\left(\frac{\sigma}{\sigma-1}\right)^{\sigma}\right]^{1 / \sigma}
$$

This is because demand for the asset will be higher, as agents in B will not pay transaction costs on the asset which is issued locally. Also, if transaction costs between B and C are lower than between $\mathrm{A}$ and $\mathrm{C}$ (which presumably will be the case with financial integration between $\mathrm{B}$ and $\mathrm{C}$ ), then demand for the asset from agents in $\mathrm{C}$ will also be higher. Hence, $z_{A}$ in equation (12) is different from $z_{A B}$ in equation (13).

Finally, in the case where an agent in A issues assets on all three markets, the profit is:

$$
p_{A B C} z_{A B C}-f\left(z_{A}\right)-3 F z_{A B C}-2 c=f^{\prime}\left(z_{A B C}\right) z_{A B C}-f\left(z_{A B C}\right) ; \quad p_{A B C}=f^{\prime}\left(z_{A B C}\right)+3 F+2 c
$$

He would then sell his asset at the highest price $p_{A B C}$ possible as demand for the asset in this case is at its maximum given the absence of transaction costs:

$$
p_{A B C}=\frac{\beta}{N} d^{1-1 / \sigma}\left[n_{A}-1+n_{B}+n_{C}+\left(\frac{\sigma}{\sigma-1}\right)^{\sigma}\right]^{1 / \sigma}
$$

Proposition 1: As transaction costs between $\mathrm{B}$ and $\mathrm{C}$ decrease, firms in country A will have an increasing incentive to issue assets in $\mathrm{B}$, the largest market of the zone. This will be at the expense of either A or $\mathrm{C}$.

Proof: It is immediate to see that the profit $\Pi(z)=f^{\prime}(z) z-f(z)$ of an agent is increasing in $z$. The number of projects $z$ is itself an increasing function of the price of the assets. Therefore, since decreasing the transaction costs between $\mathrm{B}$ and $\mathrm{C}$ leaves $p_{A}$ and $p_{A B C}$ constant but increases $p_{A B}$, the incentive to issue on market $\mathrm{B}$ increases, as financial integration between $\mathrm{B}$ and $\mathrm{C}$ proceeds.

Comparing profits obtained in (12), (13) and (15), an agent located in A will choose to issue his assets on all three financial markets if transaction costs between the three markets are high relative to the fixed costs $F$ and $c$. In this case, because of market segmentation, the price difference will be high and therefore the incentive to issue on different markets will be strong. Of course, this incentive will also be stronger, when the foreign market is larger and when there is greater foreign demand for the assets involved (the higher $n_{B}$ and $n_{C}$ ). When transaction costs between markets $\mathrm{A}$ and $\mathrm{B}$ and $\mathrm{A}$ and $\mathrm{C}$ are relatively low, then assets of $\mathrm{A}$ will only be issued in A. However, as transaction costs between $\mathrm{B}$ and $\mathrm{C}$ decrease with financial integration, the 
incentive to issue in $\mathrm{A}$ and $\mathrm{B}$ increases because issuing in $\mathrm{B}$ enables the project owner of $\mathrm{A}$ to sell with low transaction costs to agents in $\mathrm{C}$. Hence, financial integration favours the financial markets of the largest country in the integrating area. The geographical concentration of financial activities as transaction costs decrease can be illustrated by a numerical example in the Graph 2 below $^{19}$. In this example, because fixed costs are relatively high, there is never an incentive to issue on all three markets. If the fixed costs were lower, then as transaction costs between $\mathrm{B}$ and $\mathrm{C}$ decrease, issuers of $\mathrm{A}$ would at some point stop issuing on all three markets and issue only in A and B.

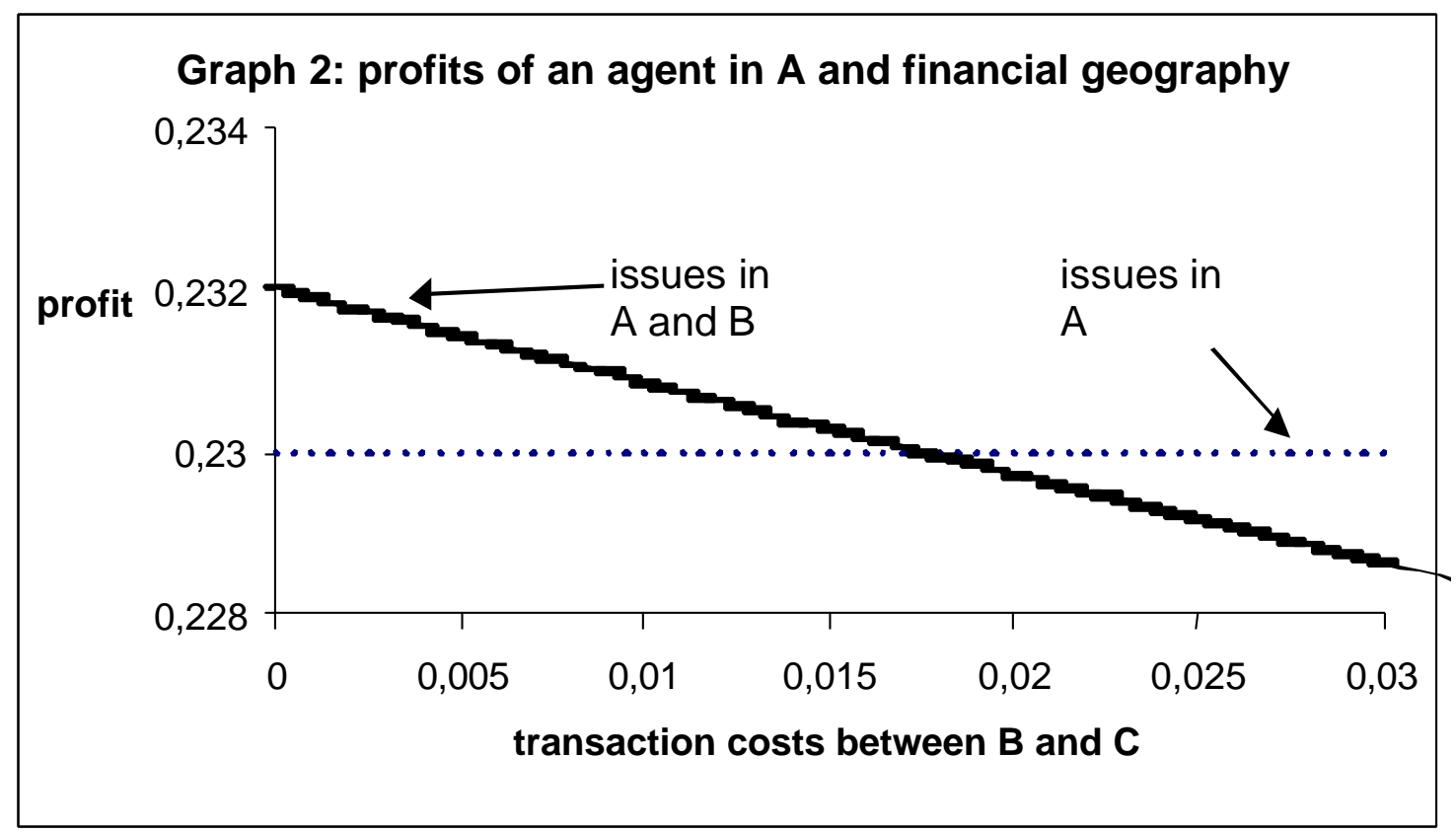

\section{Project owner of country B}

In the case of a project owner in $\mathrm{B}$, we can readily exclude the choice of issuing only in $\mathrm{C}$ (dominated by issuing in $\mathrm{B}$ only) or issuing in $\mathrm{A}$ and $\mathrm{C}$ (dominated by issuing in $\mathrm{A}$ and $\mathrm{B}$ ). This leaves five alternatives - issuing in all three markets, in A and B, in B and C, in B only and in A only.

Proposition 2: Lower transaction costs between $\mathrm{B}$ and $\mathrm{C}$ increase the incentive for firms in $\mathrm{B}$ to issue shares on their own financial markets or in market $\mathrm{A}$ for some initial conditions. This is done at the expense of market $\mathrm{C}$ and, for some initial conditions, of market $\mathrm{A}$.

Proof: The profit function is increasing in $\mathrm{z}$ and $\mathrm{z}$ is increasing in the price of assets (see proposition 1). $P_{A}, p_{A B C}, p_{B C}$ are independent of the transaction cost between $\mathrm{B}$ and $\mathrm{C}$, whereas $p_{B}$ and $p_{A B}$ are increasing when this transaction cost is reduced.

Graph 3 below shows an example ${ }^{20}$ of how the profits of a project owner in $\mathrm{B}$ change with transaction costs between $\mathrm{B}$ and $\mathrm{C}$.




In this specific example, project owners in B issue in A when transaction costs between $\mathrm{B}$ and $\mathrm{C}$ are high. This is because that in this case the segmented financial markets are too small (and therefore the price of assets is low), and it is preferable to issue only on the largest market $\mathrm{A}$. When transaction costs between $\mathrm{B}$ and $\mathrm{C}$ are sufficiently small, following financial integration between these two markets, then it becomes profitable to issue in A and B. Because issuing in $\mathrm{B}$ now implies reaching asset buyers in $\mathrm{C}$ at low transaction costs, the demand is large enough in the integrated area to sustain the fixed costs of issuing in both B and A.

We could also move from a situation where agents from country B issue only in market $\mathrm{A}$ (because transaction costs between $\mathrm{A}$ and $\mathrm{B}$ and $\mathrm{A}$ and $\mathrm{C}$ are relatively low, compared to transaction costs between $\mathrm{B}$ and $\mathrm{C}$; and the fixed cost of issuing abroad is not too high), to a situation where they issue in $\mathrm{B}$ (because of a sizeable decrease in transaction costs between $\mathrm{B}$ and $\mathrm{C}$ ). In that case the capitalisation of market $\mathrm{A}$ would decrease. Alternatively, if agents in $\mathrm{B}$ were issuing in $\mathrm{B}$ and $\mathrm{C}$ and not in $\mathrm{A}$ (because of high transaction costs between $\mathrm{A}$ and $\mathrm{C}$ and between $\mathrm{B}$ and $\mathrm{C}$ for example), then increased integration between $\mathrm{B}$ and $\mathrm{C}$ can lead them to issue in $\mathrm{A}$ and $\mathrm{B}$ and stop issuing in $\mathrm{C}$.

Other configurations are possible where for example financial integration between $\mathrm{B}$ and $\mathrm{C}$ lead project owners of $\mathrm{B}$ to switch issuing from $\mathrm{A}$ to $\mathrm{B}$, from $\mathrm{A}, \mathrm{B}$ and $\mathrm{C}$ to $\mathrm{B}$ or from $\mathrm{B}$ and $\mathrm{C}$ to $\mathrm{B}$.

\section{Project owner of country $C$}

The choice of where to issue assets for a project owner in $\mathrm{C}$ (the 'small' countries of the euro zone in the European case) is greater and therefore more complex. In all cases, financial markets in $\mathrm{B}$ gain at the expense of markets either in $\mathrm{A}$, in $\mathrm{C}$ or in both $\mathrm{A}$ and $\mathrm{C}$.

Proposition 3: There are seven possibilities for agents of country $\mathrm{C}$ to issue their assets. When financial integration between $\mathrm{B}$ and $\mathrm{C}$ proceeds, the incentives to issue in $\mathrm{C}$ only, in $\mathrm{B}$ only, in $\mathrm{A}$ and $\mathrm{C}$ and in $\mathrm{A}$ and $\mathrm{B}$ increase relative to issuing in $\mathrm{A}, \mathrm{B}$ and $\mathrm{C}$, in $\mathrm{B}$ and $\mathrm{C}$ and in $\mathrm{A}$ only.

Proof: When the transaction costs between $\mathrm{B}$ and $\mathrm{C}$ decrease, $p_{C}, p_{B}, p_{A C}, p_{A B}$ increase whereas $p_{A B C}, p_{B C}$, and $p_{A}$ are constant.

The intuition of the results is relatively straightforward: (1) when transaction costs are high relative to fixed costs and the demand in country $\mathrm{C}$ is not too small, then agents from country $\mathrm{C}$ prefer to issue shares on all markets or at least on market $\mathrm{C}$ and in one other market. This is because financial geography minimises the transaction costs; (2) when transaction costs between $\mathrm{B}$ and $\mathrm{C}$ are in a medium range relative to fixed costs, then agents from country $\mathrm{C}$ will prefer not to issue any more in market $\mathrm{C}$. In this case, transaction costs still matter so that it is preferable to issue in the largest market(s) but the fixed cost becomes relatively important so 
that it is preferable to issue on fewer markets and abandon the smallest (C); (3) when transaction costs are in the low range and the fixed cost of issuing on a foreign market is large enough (as well as the domestic demand for these assets in country $\mathrm{C}$ ), then agents in country $\mathrm{C}$ will prefer to issue only in country $\mathrm{C}$ or in $\mathrm{C}$ and $\mathrm{A}$. The reason is that now, the fixed costs are relatively the highest ones. If issuing in $\mathrm{C}$ still has an advantage for project owners of $\mathrm{C}$, because of the absence of the foreign fixed cost, then very low transaction costs

make this advantage the key determinant of location choice. This equilibrium may not exist even with very low transaction costs if the extra fixed cost to issue on the foreign market is small. Hence, in the case of the smallest country, financial integration has ambiguous effects on the issuing choice. Lower transaction costs first push towards a concentration of issuing on the largest market of the integrated area but then may give an advantage to the small market and the largest market even if outside the integrated area. Note that this pattern is similar to the one suggested by the "new economic geography" in Krugman (1991) in the context of the integration of goods markets.



Graph 4, using the same parameters as the previous graphs, illustrates one example of how transaction costs between $\mathrm{B}$ and $\mathrm{C}$ affect the choice of location in issuing for agents in $\mathrm{C}$. In this example, when transaction costs between $\mathrm{B}$ and $\mathrm{C}$ are relatively high, $\mathrm{C}$ shares are only issued in $\mathrm{A}$. Then as transaction costs between $\mathrm{B}$ and $\mathrm{C}$ decrease, $\mathrm{C}$ shares will be issued in both $\mathrm{A}$ and $\mathrm{B}$ markets. This is because $\mathrm{B}$ and $\mathrm{C}$ are now effectively a large market. As transaction costs go down further, the markets of $\mathrm{B}$ and $\mathrm{C}$ are basically the same market so that the size advantage of $\mathrm{B}$ does not matter any more. In this case, issuing in $\mathrm{C}$ becomes preferable to issuing in A and B because it eliminates the cost of issuing shares in foreign markets.

\section{Market capitalisation}

Finally, we can describe in this specific example how market capitalisations evolve with financial integration between $\mathrm{B}$ and $\mathrm{C}$. We define market capitalisation in this model as the value of sales of shares on the market. The analysis of market capitalisation follows directly from the issuing decisions studies above.

For example, we see in Graph 5 that as transaction costs between $\mathrm{B}$ and $\mathrm{C}$ decrease, market capitalisation in A decreases first when (at $\left.\tau_{\mathrm{BC}}=0.081\right) \mathrm{B}$ shares are issued in both $\mathrm{A}$ 
and B markets. Market capitalisation in B then increases a little. At $\tau_{\mathrm{BC}}=0.0175$, A shares are sold on market $A$ and market $B$ (where agents from $C$ buy them) and $C$ shares are sold both on markets $\mathrm{A}$ and $\mathrm{B}$. This implies that market capitalisation increases in $\mathrm{B}$ and decreases in $\mathrm{A}$. At $\tau_{\mathrm{BC}}=0.007, \mathrm{C}$ shares are no longer issued on markets $\mathrm{A}$ and $\mathrm{B}$ but are issued on $\mathrm{C}$. At that point market capitalisation increases in $\mathrm{C}$ and decreases in $\mathrm{A}$ and $\mathrm{B}$.

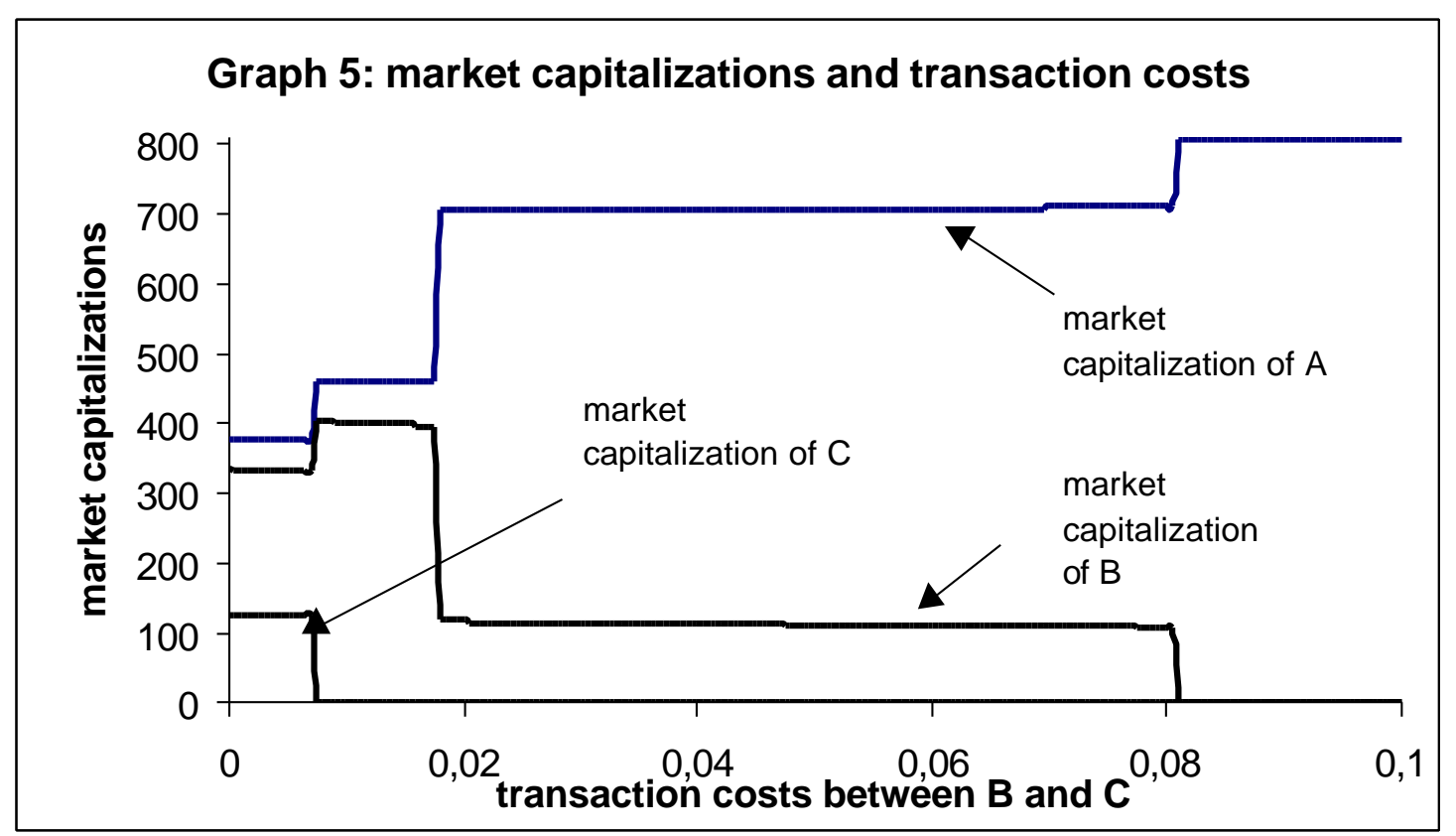

In this example, financial integration will benefit the largest market of the integrating zone at the expense of the country left out of the process. In other examples, this benefit could be at the expense of the smallest market of the integrating zone. In all cases, small markets may benefit from financial integration but only at very low levels of transaction costs. 


\section{Financial integration as a decrease in $\mathrm{c}$ within the integrated area}

Financial integration could also be interpreted as a decrease in the fixed cost of issuing on the other market. This could be due to harmonisation of institutional structures. For example, integration may lead to harmonisation of accounting standards in countries B and C. With this interpretation in mind, we assume that if agents from country B (respectively $\mathrm{C}$ ) issue shares in country C (respectively B), the fixed cost $\mathrm{c}$ of issuing on the other market decreases. Similarly if agents of country A issue in B, they pay a lower cost $\mathrm{c}$ if they issue also in $\mathrm{C}$.

Proposition 4: When financial integration between countries $\mathrm{B}$ and $\mathrm{C}$ lowers the fixed cost of issuing on the other market, agents of country B (respectively C) have a higher incentive to issue shares in $\mathrm{C}$ (respectively B); and agents of country A have higher incentives to issue both in $\mathrm{B}$ and in $\mathrm{C}$.

Proof: Profit is an increasing function of $\mathrm{z}$, the number of assets. And $\mathrm{z}$ is an increasing function of the price of assets minus the fixed costs of issuing $(\mathrm{F}+\mathrm{c}$ if one issues in a foreign market). Therefore when $\mathrm{c}$ decreases (which happens if $\mathrm{B}$ issues in $\mathrm{C}, \mathrm{C}$ in $\mathrm{B}$, or $\mathrm{A}$ issues in $\mathrm{B}$ and $\mathrm{C}$ ), then issuing in the integrated countries becomes more profitable.

Hence with this alternative interpretation of financial integration as institutional harmonisation, both countries of the integrated area may benefit, including the smallest market.

\section{Conclusion}

We have constructed a very stylised model of trade in risky assets. We have studied the impact of financial market integration on the breadth of financial market and asset returns in a threecountry world. In particular, a decrease in transaction costs between two financial markets the way we model financial integration - increases asset prices in the area, induces agents to develop more risky projects and increases the number of assets. It also pushes owners of projects to sell more of their project on the stock markets so that diversification increases.

The welfare impact for the rest of the world is ambiguous: agents can diversify risk better as markets become less incomplete but their financial terms deteriorate because the price of assets in the integrated area increases. We have also looked at the impact of international cross-listings on the price of capital and at the evolution of the geography of financial centres as transaction costs decline. The relative magnitudes of the fixed and variable costs that agents incur to get listed on stock exchanges or to engage in equity trade are the key determinants. Financial integration increases the incentive to issue shares on the largest market of the integrated area. Depending on the initial conditions, the outside market, if large enough, may also attract new issuings of firms of the integrated area.

Existing empirical evidence, as discussed in the introduction, is consistent with our findings. Financial integration decreases significantly the cost of capital, and demand effects on the price of assets have been documented. The voluminous literature on international crosslistings is also consistent with the predictions of our model. Moreover, as far as we know, our model is the only one able to explain reasonably well the pattern of gross equity flows. We are not claiming, however, that our class of models is the only one consistent with those empirical facts. It would be very interesting to go on comparing the performance of our modelling approach to the performance of more "traditional" models: the most likely candidate would probably be some extensions of the international CAPM with information asymmetries following Merton 1987 or Brennan and Cao 1997, for example. The questions we address in this paper have however been greatly overlooked by traditional finance literature which has almost exclusively focused on prices and stocks, rather than flows. Market incompleteness and transaction costs, non-representative agents and aggregate risk, which emerge very naturally in 
our framework are also non-orthodox ingredients of classic finance and macroeconomic models. 


\section{References}

Acemoglu, D. and Zilibotti, F. (1997), 'Was Promotheus Unbound by Chance? Risk, Diversification and Growth ', Journal of Political Economy, Vol. 105, pp.709-751.

Alexander, C. and Janakiraman, S. (1988), 'International Listings and Stock Returns: Some Empirical Evidence', Journal of Financial and Quantitative Analysis, Vol. 23, pp.135-151.

Allen, F. and Gale, D. (1994), 'Financial Innovation and Risk Sharing', MIT Press.

Amihud, Y. and Mendelson, H. (1986), 'Asset Pricing and the Bid Ask Spread', Journal of Financial Economics, Vol. 17, pp.223-249.

Bekaert, G. and Harvey, C. (1998), 'The Effects of Market Segmentation and Investor Recognition on Asset Prices: Evidence from Foreign Stocks listing in the US', Journal of Finance, forthcoming.

Brennan and Cao, (1997), 'International Portfolio Investment Flows', Journal of Finance, Vol. 5, pp.1851-1879.

Gehrig, T. (1998), 'Competing Markets', European Economic Review, Vol.42(1).

Gehrig, T. (1999), 'Cities and the Geography of Financial Centres', in Thisse and Huriot (eds) Economics of Cities.

Hardouvelis, G., Malliaropulos, D. and Priestley, R. (1999), 'EMU and European Stock Market Integration', CEPR DP 2124, April.

Harris, L. and Gurel, E. (1986), 'Price and Volume Effects Associated With Changes in the S\&P 500 list: new evidence for the existence of price pressure', Journal of Finance, Vol. 41, pp.815-829.

Helpman, E. and Razin, A. (1978) A Theory of International Trade under Uncertainty Academic Press: New York.

Henry, P. (1998), 'Stock Market Liberalisation, Economic Reform, and Emerging Market Prices', unpublished working paper, Stanford university, Palo Alto, CA.

Karolyi, A (1998), 'Why do Companies List Abroad? A Survey of the Evidence and its Managerial Implications', New York University Salomon Brothers Center, New York: NY.

Lombardo, D. and Pagano, M. (1999), 'Law and Equity Markets: A Simple Model', Paper prepared for the Conference on 'Convergence and diversity in corporate governance regimes and capital markets', Tilburg University, 4-5 November 1999.

Martin, P. and Rey, H. (2000), 'Financial Super-Markets: Size Matters for Asset Trade', Discussion Paper No. 450, Centre for Economic Performance, London School of Economics. 
Merton, R. (1987), 'Presidential Address: a Simple Model of Capital Market Equilibrium With Incomplete Information', Journal of Finance, Vol. 42, pp.483-510.

Miller, D. (1999), 'The Market Reaction to International Cross-Listings: Evidence from Depositary Receipts', Journal of Financial Economics, Vol. 51, pp.103-123.

Obstfeld, R. (1996), 'Foundations of International Macroeconomics’, MIT Press.

Pagano, M. (1988), 'Trading Volume and Asset Liquidity', Quarterly Journal of Economics, pp.255-274.

Pagano, M. (1989), 'Endogenous Market Thinness and Stock Price Volatility', Review of Economic Studies, Vol. 56, pp.269-288.

Pagano, M. (1993), 'The Flotation of Companies on the Stock Market: a Coordination Failure Model', European Economic Review, Special Issue on Finance, Vol. 37, No. 5, June.

Persson, T. and Svensson, L. (1989), 'Exchange Rate Variability and Asset Trade', Journal of Monetary Economics, Vol. 23, pp.485-509.

Portes, R. and Rey, H. (1998), 'The Emergence of the Euro as an International Currency', Economic Policy, Vol. 26.

Portes, R. and Rey, H. (2000), 'Determinants of Cross-Border Equity Flows', Discussion Paper No. 446, Centre for Economic Performance, London School of Economics.

Shleifer, A., (1986), ‘Do Demand Curves For Stocks Slope Down?', Journal of Finance, Vol. 41, pp.579-590.

Stulz, R. (1999a), 'Globalization of Equity Markets and the Cost of Capital', paper prepared for the SBF/NYSE Conference on Global Equity Markets.

Stulz, R. (1999b), 'International Portfolio Flows and Security Markets', mimeo, Ohio State University.

Svensson, L. E. O., (1988), 'Trade in Risky Assets', American Economic Review, Vol. 8, pp.375-394.

Svensson, L. E. O., (1989), 'Trade in Nominal Assets', Journal of International Economics, Vol. 26, pp.1-28.

Vayanos, D. (1998), 'Transaction Costs and Asset Prices: A Dynamic Equilibrium Model', The Review of Financial Studies, Vol. 11, No. 1, Spring. 